\title{
Cullin-1 and -2 Protein Expression in Colorectal Cancer: Correlation with Clinicopathological Variables
}

\author{
OTHON MICHAIL ${ }^{1}$, DEMETRIOS MORIS $^{2}$, STAMATIOS THEOCHARIS ${ }^{3}$ and JOHN GRINIATSOS ${ }^{1}$ \\ ${ }^{1}$ First Department of Surgery, Laikon General Hospital, \\ National and Kapodistrian University of Athens, Athens, Greece; \\ ${ }^{2}$ Department of Surgery, Duke University Medical Center, Durham, NC, U.S.A.; \\ ${ }^{3}$ Department of Forensic Medicine and Toxicology, Laikon General Hospital, \\ National and Kapodistrian University of Athens, Athens, Greece
}

\begin{abstract}
Background/Aim: The cullin (CUL) family of proteins is involved in the ubiquitin/mediated degradation of proteins, regulating cell proliferation, cell-cycle control, migration, invasion and metastasis in the process of tumor progression. The aim of the present study was to examine if there is any correlation between the immunohistochemical (IHC) expression of Cullin-1 and -2 proteins in colorectal cancer tissue specimens with several clinicopathological variables. Materials and Methods: Between January 2012 and December 2014, 96 consecutive adenocarcinoma patients were submitted to oncological colectomy, as the first therapeutic option, with a curative intent. CUL-1 and -2 protein expression was examined with IHC on paraffinembedded tissue sections. CUL-1 and -2 protein positivity, was correlated with patients' age, gender, stage, histological grade, proliferative capacity (Ki-67 labeling index) and mutant 553 protein expression. The positivity for CUL-1, CUL-2, mutant 553 protein and Ki-67 index, was determined by the percentage of their IHC expression in the total number of cancer cells. Results: Choosing as a cut-off point for CUL-1 positivity the 10\%, a statistically significant relationship of the expression of the mutant $p 53$ protein $(p=0.04)$ and the coexpression of CUL-2 ( $p=0.003)$ were noticed. By setting the cut-off limit for CUL-2 expression to $10 \%$, no statistically significant differences were observed between its expression and the examined clinicopathological variables. However, by increasing the cut-off limit for CUL-2 expression to 30\%, a statistically significant correlation of its expression to the
\end{abstract}

This article is freely accessible online.

Correspondence to: Demetrios Moris, Department of Surgery, Duke University Medical Center, Durham, NC, U.S.A. Tel: +1 2165716614, Fax: +1 2165716614, e-mail: dimmoris@yahoo.com

Key Words: Cullins, cullin-1, cullin-2, colorectal cancer, prognosis. mutated p53 protein was noticed ( $p=0.047)$. Co-expression of CUL-1 and -2 in more than 10\%, significantly correlated to the coexistence of adenomatous polyps along the large bowel $(p=0.0329)$. Multivariate analysis of CUL-1 and -2 coexpression in more than $10 \%$ disclosed their expression as an independent factor for adenomatous polyps development in the large bowel $(p=0.035, R R=2.1)$. Conclusion: CUL-1 overexpression may happen early in the process of carcinogenesis mainly affecting the vulnerable p53(+) large bowel cells, arresting them in the G1 phase of cell-cycle, while it may also induce the expression of CUL-2. Coexpression of CUL-1 and CUL-2, in the arrested (in G1 phase) large bowel cells, promotes carcinogenesis up to adenomatous polyp formation. Since no relationship between cullins expression and development of cancer on adenoma was found, the results of the present study may be useful explaining the initiation but not the progression of carcinogenesis in colorectal cancer. Further molecular and clinical studies are needed in order to delineate the clinical importance of these proteins in the management of colorectal cancer patients.

Several biological processes such as proliferation, differentiation, apoptosis, migration, invasion, signal transduction, transcription, cell-cycle progression and cell death, (1) depend precisely on the timely synthesis and degradation of key regulatory proteins (2).

While protein synthesis can be regulated at multiple levels, protein degradation is mainly controlled by the ubiquitin - proteasome system (UPS) $(2,3)$ which consists of two distinct steps: ubiquitination of targeted proteins by E1 ubiquitin-activating enzyme, E2 ubiquitin-conjugating enzyme and E3 ubiquitin ligase, (4) and subsequent degradation by the $26 \mathrm{~S}$ proteasome $(4,5)$.

Among all E3 ubiquitin ligases, the SCF (SKP1-CUL1-Fbox protein) E3 ligases are the largest family and are responsible for the turnover of many key regulatory proteins 
(6). Similarly to other post-translational modifications, the process of ubiquitination is reversible, with the removal of ubiquitin from substrates regulated by deubiquitinating enzymes (7). Up to date, more than 600 E3 ubiquitin ligases and 100 de-ubiquitinating enzymes have been identified, forming a molecular network governing intracellular ubiquitination dynamics (8).

Dysregulation of the proteolytic system results in uncontrolled proliferation, genomic instability and cancer (1). Aberrant regulation of SCF E3 ligases is associated with various human diseases, such as cancers (2) while, misregulated expression of the members of the ubiquitination cascade, attributes a cancerous phenotype to various cells including enhanced proliferation, survival and metastatic potential (9).

Cullins (CUL) are a protein family acting as a matrix for E3-ubiquitin ligases. CUL1 is an essential scaffold of the SKP1-CUL1-F-box protein (SCF) E3 ubiquitin ligase complex, (6) which mediates the ubiquitination of proteins involved in cell-cycle induction and progression (3). CUL-1 is required for the developmentally programmed transitions from the $G_{1}$ to the $G_{0}$ phase of the cell cycle or the apoptotic pathway. Moreover, the mutant phenotype suggests that $\mathrm{G}_{1}$ to-S phase progression is accelerated, overriding mechanisms for mitotic arrest and producing abnormally small cells (10). Cullin-2 (CUL-2) interacts with the trimeric von Hippel Lindau-elongin B-elongin $\mathrm{C}$ complex and plays an essential role in the degradation of hypoxia-inducing factor $1 \alpha$ by ubiquitination (11).

On the other hand, knockdown of CUL-1 inhibits cell growth, proliferation, migration and invasion (mainly by upregulating p27 expression) $(12,13)$ in cases of melanoma (12), gastric cancer (13), lung cancer (14), breast cancer (15) and skin cancer (16), by arresting cells in the $G_{1}$ phase (16).

The aim of the present study was to examine if there was any correlation between the immunohistochemical (IHC) expression of CUL-1 and CUL-2 proteins in colorectal cancer tissue specimens to several clinicopathological variables.

\section{Materials and Methods}

Patients. From 2011 onwards, all patients who were referred to our Department for further investigation and treatment, having been diagnosed with colorectal cancer, were prospectively collected. Demographics, clinical data, adjuvant or neo-adjuvant therapies, type of operation, postoperative complications, histological findings and follow-up, were recorded.

All patients suffered from colorectal cancer and had undergone colonoscopy and biopsies for histological confirmation of the disease. All of them were submitted at least to computer tomography (CT) of thorax and abdomen for staging of the disease, while patients suffering from rectal tumors were further submitted to magnetic resonance imaging (MRI) of the pelvis for loco-regional staging of the disease (17).
Table I. Clinicopathological characteristics of the enrolled patients.

\begin{tabular}{|c|c|}
\hline \multicolumn{2}{|l|}{ Gender } \\
\hline Male & 43 \\
\hline Female & 53 \\
\hline \multicolumn{2}{|l|}{ Age } \\
\hline Median + Interquartile Range (IR) & $70(63-77)$ \\
\hline \multicolumn{2}{|l|}{ Location of the primary tumor } \\
\hline Cecum-Ascending colon & 15 \\
\hline Transverse colon & 5 \\
\hline Descending-Sigmoid colon & 47 \\
\hline Rectum & 29 \\
\hline \multicolumn{2}{|l|}{ Grade } \\
\hline 1 & 21 \\
\hline 2 & 62 \\
\hline 3 & 13 \\
\hline \multicolumn{2}{|l|}{ Stage } \\
\hline A & 23 \\
\hline $\mathrm{B}$ & 33 \\
\hline $\mathrm{C} 1$ & 23 \\
\hline $\mathrm{C} 2$ & 17 \\
\hline \multicolumn{2}{|l|}{ Cancer on adenoma } \\
\hline Yes & 18 \\
\hline No & 78 \\
\hline \multicolumn{2}{|l|}{ Coexistence of adenomas } \\
\hline Yes & 29 \\
\hline No & 67 \\
\hline \multicolumn{2}{|l|}{ Vascular invasion } \\
\hline Yes & 24 \\
\hline No & 72 \\
\hline
\end{tabular}

Excluding patients (i) who were diagnosed with histological types others than adenocarcinoma, (ii) who were operated on for palliation, (iii) who were classified as suffering from locally advanced disease and referred for neo-adjuvant therapies, (iv) who were diagnosed as stage IV, even though a curative resection was achieved and (v) who suffered from multiple distant metastases and referred for systematic chemotherapy, a total of 96 consecutive adenocarcinoma patients were submitted to oncological colectomy, as a first therapeutic option, with curative intent, between January 2012 and December 2014.

The pathological stage of the disease was based on the 7th TNM Classification, (18) while tumor grade was based on the WHO classification (19).

Immunohistochemical (IHC) staining. Tissue blocks were extracted from the surgical specimen and subjected to immunohistochemical (IHC) staging. Paraffin embedded biopsy specimens were used. The method used is as follows: One 4- $\mu \mathrm{m}-$ thick section was cut from 1 representative paraffin block of each case. The sections were floated onto salinized glass slides, dried out at $37^{\circ} \mathrm{C}$ overnight, and then kept at $60^{\circ} \mathrm{C}$ for 1 hour, before de-paraffinization in xylene and rehydration through graded ethanol. All sections were subjected to microwave heating at 850 $\mathrm{W}$ for $22 \mathrm{~min}$ in $\mathrm{pH} 6.0$ citrate buffer and cooled in running water. The antibodies used were mouse cullin-1 and 2 (Novus Biological, Littleton, CO, USA), pRB (Santa Cruz Biotechnology, Dallas, TX, USA), Ki-67 (DAKO, Poland, Warsaw), dilution 1:50 
Table II. Univariate analysis between expression of cullin- $1 \geq 10 \%$ and evaluated parameters.

\begin{tabular}{lccc}
\hline Parameter & Cullin-1 & Cullin-1 & $p$-Value \\
& $\geq 10 \%$ & $<10 \%$ & \\
& $(\mathrm{n}=75)$ & $(\mathrm{n}=21)$ &
\end{tabular}

\begin{tabular}{|c|c|c|c|}
\hline \multicolumn{4}{|l|}{ Gender } \\
\hline Male & 31 & 12 & \\
\hline Female & 44 & 9 & \\
\hline \multicolumn{4}{|l|}{ Age } \\
\hline (Median+IR) & $70(63.5-77)$ & $69(63-80)$ & \\
\hline \multicolumn{4}{|l|}{$\begin{array}{l}\text { Location of the } \\
\text { primary tumor }\end{array}$} \\
\hline Right colon & 17 & 3 & \\
\hline Left colon & 36 & 11 & \\
\hline Rectum & 22 & 7 & \\
\hline \multicolumn{4}{|c|}{$\begin{array}{l}\text { Size of the primary } \\
\text { tumor }(\mathrm{mm})\end{array}$} \\
\hline (Median+IR) & $50(40-70) \mathrm{mm}$ & $75(50-90) \mathrm{mm}$ & \\
\hline \multicolumn{4}{|l|}{ Grade } \\
\hline 1 & 16 & 5 & \\
\hline 2 & 49 & 13 & \\
\hline 3 & 10 & 3 & \\
\hline \multicolumn{4}{|l|}{ Stage } \\
\hline I & 18 & 5 & \\
\hline IIA & 10 & 5 & \\
\hline IIB & 13 & 5 & \\
\hline IIIA & 21 & 2 & \\
\hline IIIB & 13 & 4 & \\
\hline \multicolumn{4}{|c|}{ Nodal Infiltration } \\
\hline Yes & 33 & 6 & \\
\hline No & 42 & 15 & \\
\hline \multicolumn{4}{|c|}{ Cancer on adenoma } \\
\hline Yes & 15 & 3 & \\
\hline No & 6018 & & \\
\hline \multicolumn{4}{|c|}{ Coexistence of adenomas } \\
\hline Yes & 24 & 5 & \\
\hline No & 51 & 16 & \\
\hline \multicolumn{4}{|c|}{ Vascular invasion } \\
\hline Yes & 18 & 6 & \\
\hline No & 57 & 15 & \\
\hline \multicolumn{4}{|c|}{ Cullin-2 expression } \\
\hline Positive & 47 & 15 & \\
\hline Negatve & 28 & 6 & \\
\hline \multicolumn{4}{|c|}{ Cullin-2 expression $(\%)$} \\
\hline (Median+IR) & $60(37.5-72.5)$ & $35(20-45)$ & 0.003 \\
\hline \multicolumn{4}{|l|}{ Ki-67 (\%) } \\
\hline (Median+IR) & $20(10-37)$ & $16(3-25)$ & \\
\hline \multicolumn{4}{|l|}{ Mutant p53 (\%) } \\
\hline (Median+IR) & $43.5(2.25-68.75)$ & $2(2-58)$ & 0.04 \\
\hline
\end{tabular}

at room temperature for 1 hour. IHC staining was carried out using an HRP polymer detection envision method (DAKO EnVision+ System, Poland, Warsaw). Diaminobenzidine (DAB) was used as chromogen and sections were counterstained with Harris' hematoxylin. Appropriate positive and negative controls omitting the primary antibodies were included with each slide run.
Table III. Univariate analysis between co-expression of cullin-1 and -2 in percentage $\geq 10$ and evaluated parameters.

\begin{tabular}{|c|c|c|c|}
\hline Parameter & $\begin{array}{c}\text { Cullin } 1 \\
+2 \text { pos } \\
(\mathrm{n}=47)\end{array}$ & $\begin{array}{l}\text { Cullin } \\
1+2 \text { neg } \\
(\mathrm{n}=49)\end{array}$ & $p$-Value \\
\hline \multicolumn{4}{|l|}{ Gender } \\
\hline Male & 20 & 23 & \\
\hline Female & 27 & 26 & \\
\hline \multicolumn{4}{|l|}{ Age } \\
\hline (Median+IR) & $69(63-76.5)$ & $70(63-78)$ & \\
\hline \multicolumn{4}{|l|}{$\begin{array}{l}\text { Location of the } \\
\text { primary tumor }\end{array}$} \\
\hline Right colon & 11 & 10 & \\
\hline Left colon & 23 & 20 & \\
\hline Rectum & 13 & 19 & \\
\hline \multicolumn{4}{|c|}{$\begin{array}{l}\text { Size of the primary } \\
\text { tumor }(\mathrm{mm})\end{array}$} \\
\hline (Median+IR) & $50(30-65) \mathrm{mm}$ & $52(40-70) \mathrm{mm}$ & \\
\hline \multicolumn{4}{|l|}{ Grade } \\
\hline 1 & 11 & 10 & \\
\hline 2 & 31 & 31 & \\
\hline 3 & 5 & 8 & \\
\hline \multicolumn{4}{|l|}{ Stage } \\
\hline A & 10 & 13 & \\
\hline IIA & 7 & 8 & \\
\hline IIB & 9 & 9 & \\
\hline IIIA & 11 & 12 & \\
\hline IIIB & 10 & 7 & \\
\hline \multicolumn{4}{|c|}{ Nodal infiltration } \\
\hline YES & 20 & 19 & \\
\hline No & 27 & 30 & \\
\hline \multicolumn{4}{|c|}{ Cancer on adenoma } \\
\hline Yes & 10 & 8 & \\
\hline No & 37 & 41 & \\
\hline \multicolumn{4}{|c|}{ Coexistence of adenomas } \\
\hline Yes & 19 & 10 & \\
\hline No & 28 & 39 & 0.0329 \\
\hline \multicolumn{4}{|c|}{ Vascular invasion } \\
\hline Yes & 11 & 13 & \\
\hline No & 36 & 36 & \\
\hline \multicolumn{4}{|l|}{ Mutant p53 (\%) } \\
\hline (Median+IR) & $50.5(14-70)$ & $12(2-66)$ & 0.064 \\
\hline \multicolumn{4}{|l|}{ Ki-67 (\%) } \\
\hline (Median+IR) & $25(12-38)$ & $17(4-27)$ & 0.070 \\
\hline
\end{tabular}

The percentage of cells expressing CUL-1, CUL-2, mutant p53 protein and $\mathrm{Ki}-67$ index as assayed by IHC was determined and all examined parameters were correlated with patient's age, gender, stage of the disease, tumor histological grade, tumor proliferative activity (Ki-67 labeling index) and mutant p53 protein expression.

Statistical analysis. For the correlation between CUL and the clinicopathological variables the chi-square test was used. $p$-Value with statistical significance was set at $p<0.05$. For statistical analysis the SPSS (version 18) statistical package, was used. 
Table IV. Multivariate analysis of Cullin-1 and -2 co-expression.

\begin{tabular}{|c|c|c|c|c|}
\hline Parameter & $p$-Value & $\mathrm{RR}$ & \multicolumn{2}{|c|}{$95 \%$ confidence interval } \\
\hline Gender & 0.3804 & & -0.303629907 & 0.117041852 \\
\hline Age & 0.2777 & & -0.004205792 & 0.014467191 \\
\hline Size of the primary tumor & 0.5693 & & -0.00328034 & 0.005925968 \\
\hline Cancer on adenoma & 0.8411 & & -0.266702225 & 0.32673951 \\
\hline Coexistence of adenoma & 0.03568 & 2.1 & 0.017614692 & 0.496853876 \\
\hline Vascular invasion & 0.8020 & & -0.213376221 & 0.275200965 \\
\hline Ki-67 & 0.2483 & & -0.009402992 & 0.002463997 \\
\hline Mutant p53 & 0.1161 & & -0.005892596 & 0.00065998 \\
\hline
\end{tabular}

\section{Results}

There were 96 patients with a median age of 70 years (IR: 6377 years), who underwent oncological colectomy for colorectal adenocarcinoma. The clinicopathological characteristics of the patients enrolled, are presented in Table I.

Univariate analysis between CUL-1 expression to several clinicopathological variables. Choosing as a cut-off point for CUL-1 positivity the $10 \%$ (Table II), 75 specimens (78\%) were characterized as positive and statistically significantly related to the expression of mutant $\mathrm{p} 53$ protein $(p=0.04)$ and the co-expression of CUL-2 ( $p=0.003)$.

By setting the cut-off limit for CUL-1 expression to $30 \%$, 36 specimens $(37.5 \%)$ were characterized as positive. The statistical significance to the CUL-2 co-expression was preserved $(p=0.02)$, although a slight decrease of the statistical significance between CUL-1 expression and the mutant p53 protein expression was observed $(p=0.07)$.

Univariate analysis between CUL-2 expression to several clinicopathological variables. By setting the cut-off limit for CUL-2 expression to $10 \%, 62$ specimens (64.5\%) were considered positive. No statistically significant differences were observed between CUL- $2>10 \%$ expression and the examined clinicopathological variables.

By increasing the cut-off limit for CUL-2 expression to $30 \%, 44$ specimens (46\%) were considered positive. A statistically significant correlation of its expression to the mutated p53 protein was noticed $(p=0.047)$.

Univariate analysis between CUL-1 \& 2 expressions $\geq 10 \%$ to several clinicopathological variables. By setting the cutoff point for both CUL expressions to $10 \%, 47$ specimens (49\%), were considered positive (Table III). A statistically significant correlation between their co-expression to the coexistence of adenomatous polyps along the large bowel $(p=0.0329)$, as well as a nearly statistically significant correlation to mutant $\mathrm{p} 53$ protein expression $(p=0.064)$ and Ki-67 expression $(p=0.07)$ were observed.
Multivariate analysis of CUL-1 and -2 co-expression. Multivariate analysis (Table IV) of CUL-1 and -2 coexpression in more than $10 \%$ disclosed their expression as an independent factor for adenomatous polyp development along the large bowel $(p=0.035, \mathrm{RR}=2.1)$.

\section{Discussion}

The present study disclosed that $78 \%$ of the colorectal cancers analysed, expressed CUL-1. The prognostic significance of CUL expression in colorectal cancer has been studied by Wang et al. (20) who found that high CUL-1 expression was positively associated with a larger primary tumor diameter and lymph node metastasis, revealing that high CUL1 expression was an independent unfavourable prognostic factor for colorectal cancer patients. Similarly, Jiang et al. (21) addressed that high CUL4B expression was significantly associated with the depth of tumor invasion, lymph node metastasis, distant metastasis, histological differentiation, vascular invasion, and advanced tumor stage, while patients with CUL4B-positive tumors, had a higher recurrence rate and a poorer survival compared to those with CUL4B-negative tumors, finally concluding that CUL4B expression was an independent factor for determining colon cancer prognosis after surgery. Both studies $(20,21)$ addressed that CUL expression was significantly upregulated in colorectal tumor tissue compared to the paired normal mucosa, both in vitro and in vivo.

The present study did not provide similar results, however disclosed that CUL-1 expression was statistically significantly related to the expression of mutant $\mathrm{p} 53$. Since the expression of mutant p53 protein represents a well-known independent dismal prognostic factor for sporadic colorectal cancer (22, 23) and TP53 mutant cancer cells tend to be more resistant to a range of cytotoxic drugs, (24) the present study indirectly indicates a potential unfavorable prognostic role for CUL-1.

Although CUL-1 expression did not directly correlate to CUL-2 expression, the present study addressed that CUL-1(+) tumors overexpress CUL-2, an also indirect 
finding for inductiveness of CUL-1 on CUL-2 expression.

A potentially clinically interesting observation of the present study is that neither the expression of CUL-1 or CUL2 nor their co-expression, promoted carcinogenesis on an adenomatous polyp. However, multivariate analysis disclosed CUL-1 and CUL-2 co-expression as an independent factor favoring adenomatous polyp development in the large bowel.

Inactivation or loss of the TP53 gene is a prerequisite for tumor growth (25). Mutant p53 not only loses its anti-tumor transcriptional activity, but also often acquires oncogenic functions to promote tumor proliferation and invasion (26). The present study indicates that in these vulnerable mutant p53(+) large bowel cells, CUL-1 overexpression happens at an early stage of carcinogenesis arresting cells in the G1 phase (16) and may also induct the expression of CUL-2. Co-expression of CUL-1 and CUL-2 promotes carcinogenesis further, to adenomatous polyp formation in the large bowel. In the absence of hereditary syndromes, adenomatous polyps represent a predisposing but not a definite causative factor for colorectal cancer development. Further research regarding the malignant progression from adenoma status requires cellular and molecular pathways unable to be explained based only on clinical observations.

\section{Conclusion}

The results of the present study indicate that CUL-1 overexpression may happen early in the process of carcinogenesis mainly affecting the vulnerable p53(+) large bowel cells, arresting them in the $\mathrm{G}_{1}$ phase of cell-cycle, while it may also induct the expression of CUL-2. Co-expression of CUL-1 and CUL-2 in $\mathrm{G}_{1}$ phase-arrested large bowel cells promotes carcinogenesis. Since no relationship between cullin expression and development of adenocarcinoma was found, the results of the present study may be useful in explaining the initiation but not the progression of carcinogenesis in colorectal cancer. Further molecular and clinical studies are needed in order to delineate the clinical importance of these proteins in the management of colorectal cancer patients.

\section{Conflicts of Interest}

None.

\section{References}

1 Zheng N, Zhou Q, Wang Z and Wei W: Recent advances in SCF ubiquitin ligase complex: clinical implications. Biochim Biophys Acta 1866: 12-22, 2016.

2 Xie CM, Wei W and Sun Y: Role of SKP1-CUL1-F-Box-Protein (SCF) E3 ubiquitin ligases in skin cancer. J Genet Genomics 40(3): 97-106, 2013.

3 Nakayama KI and Nakayama K: Ubiquitin ligases: cell-cycle control and cancer. Nature Rev Cancer 6: 369-381, 2006.
$4 \mathrm{Ma} \mathrm{J}$, Guo $\mathrm{W}$ and $\mathrm{Li} \mathrm{C}$ : Ubiquitination in melanoma pathogenesis and treatment. Cancer Med 6: 1362-1377, 2017.

5 Bedford L, Lowe J, Dick LR, Mayer RJ and Brownell JE: Ubiquitin-like protein conjugation and the ubiquitin-proteasome system as drug targets. Nat Rev Drug Discov 10: 29-46, 2011.

6 Zheng N, Schulman BA, Song L, Miller JJ, Jeffrey PD, Wang P, Chu C, Koepp DM, Elledge SJ, Pagano M, Conaway RC, Conaway JW, Harper JW and Pavletich NP: Structure of the Cul1-Rbx1-Skp1-F boxSkp2 SCF ubiquitin ligase complex. Nature 416(6882): 703-709, 2002.

7 ReyesTurcu FE, Ventii KH and Wilkinson KD: Regulation and cellular roles of ubiquitin-specific deubiquitinating enzymes. Annu Rev Biochem 78: 363-397, 2009.

8 Grabbe C, Husnjak K and Dikic I: The spatial and temporal organization of ubiquitin networks. Nat Rev Mol Cell Biol 12: 295-307, 2011.

9 Gallo LH, Ko J and Donoghue DJ: The importance of regulatory ubiquitination in cancer and metastasis. Cell Cycle 16: 634-648, 2017.

10 Kipreos ET, Lander LE, Wing JP, He WW and Hedgecock EM: cul-1 is required for cell cycle exit in C. elegans and identifies a novel gene family. Cell 85: 829-839, 1996.

11 Pause A, Lee S, Worrell RA, Chen DY, Burgess WH, Linehan WM and Klausner RD: The von hippel-lindau tumor-suppressor gene product forms a stable complex with human cul-2, a member of the cdc53 family of proteins. Proc Natl Acad Sci USA 94: 2156-2161, 1997.

12 Chen $\mathrm{G}$ and $\mathrm{Li} \mathrm{G}$ : Increased cul1 expression promotes melanoma cell proliferation through regulating p27 expression. Int J Oncol 37: 1339-1344, 2010.

13 Bai J, Zhou Y, Chen G, Zeng J, Ding J, Tan Y, Zhou J and Li G: Overexpression of cullin1 is associated with poor prognosis of patients with gastric cancer. Hum Pathol 42: 375-383, 2011.

14 Salon C, Brambilla E, Brambilla C, Lantuejoul S, Gazzeri S and Eymin B: Altered pattern of cul-1 protein expression and neddylation in human lung tumours: Relationships with cand1 and cyclin e protein levels. J Pathol 213: 303-310, 2007.

15 Bai J, Yong HM, Chen FF, Mei PJ, Liu H, Li C, Pan ZQ, Wu YP and Zheng JN: Cullin1 is a novel marker of poor prognosis and a potential therapeutic target in human breast cancer. Ann Oncol 24: 2016-2022, 2013.

16 Xie CM, Wei W and Sun Y: Role of skp1-cul1-f-box-protein (scf) e3 ubiquitin ligases in skin cancer. J Genet Genomics 40: 97-106, 2013.

17 Balyasnikova S and Brown G: Optimal imaging strategies for rectal cancer staging and ongoing management. Curr Treat Options Oncol 17: 32, 2016.

18 Sobin LH, Gospodarowicz MK and Wittekind C: TNM classification of malignant tumors, 7th edition, Wiley-Blackwell, 2011.

19 Kleihues $\mathrm{P}$ and Sobin LH: World health organization classification of tumors. Cancer 88: 2887, 2000.

20 Wang W, Chen Y, Deng J, Zhou J, Gu X, Tang Y, Zhang G, Tan Y, Ge Z, Huang Y, Wang S, Zhou J, Zhou Y and Zhou S: Cullin1 is a novel prognostic marker and regulates the cell proliferation and metastasis in colorectal cancer. J Cancer Res Clin Oncol 141: 1603-1612, 2015.

21 Ziang T, Tang HM, Wu ZH, Chen J, Lu S, Zhou CZ, Yan DW and Peng $\mathrm{ZH}$ : Cullin $4 \mathrm{~b}$ is a novel prognostic marker that correlates with colon cancer progression and pathogenesis. Med Oncol 30: 534, 2013. 
22 Westra JL, Schaapveld M, Hollema H, de Boer JP, Kraak MM, de Jong D, ter Elst A, Mulder NH, Buys CH, Hofstra RM and Plukker JT: Determination of TP53 mutation is more relevant than microsatellite instability status for the prediction of diseasefree survival in adjuvant-treated stage III colon cancer patients. J Clin Oncol 23: 5635-5643, 2005.

23 Chang SC, Lin JK, Yang SH, Wang HS, Li AF and Chi CW: Relationship between genetic alterations and prognosis in sporadic colorectal cancer. Int J Cancer 118: 1721-1727, 2006.

$24 \mathrm{Hu} \mathrm{T}$, Li Z, Gao CY and Cho $\mathrm{CH}$ : Mechanisms of drug resistance in colon cancer and its therapeutic strategies. World $\mathbf{J}$ Gastroenterol 22: 6876-6889, 2016.
25 Merkel O, Taylor N, Prutsch N, Staber PB, Moriggl R, Turner SD and Kenner L: When the guardian sleeps: Reactivation of the p53 pathway in cancer. Mutat Res 773: 1-13, 2017.

26 Zhao D, Tahaney WM, Mazumdar A, Savage MI and Brown PH: Molecularly targeted therapies for p53-mutant cancers. Cell Mol Life Sci 74: 4171-4187, 2017.

Received December 2, 2017

Revised December 29, 2017 Accepted January 3, 2018 